\title{
$17 \beta$-estradiol protects human skin fibroblasts and keratinocytes against oxidative damage
}

\author{
G. Bottai, ${ }^{\dagger}$ R. Mancina, ${ }^{\dagger}$ M. Muratori, ${ }^{\ddagger}$ P. Di Gennaro, ${ }^{\dagger}$ T. Lotti $^{\S}, \star$ \\ ${ }^{\dagger}$ Department of Critical Care Medicine and Surgery, Division of Clinical, Preventive and Oncology Dermatology, University of \\ Florence, Florence, Italy \\ ‡Department of Clinical Physiopathology, Andrology Unit, and Center of Excellence 'DeNothe', University of Florence, Florence, \\ Italy \\ §Dermatology and Venereology Division, University of Rome "G. Marconi”, Rome, Italy \\ *Correspondence: T. Lotti. E-mail: professor@torellolotti.it
}

\begin{abstract}
Background Reactive oxygen species (ROS) cause severe damage to extracellular matrix and to molecular structure of DNA, proteins and lipids. Accumulation of these molecular changes apparently constitutes the basis of cell ageing. 17b-estradiol (E2) has a key role in skin ageing homeostasis as evidenced by the accelerated decline in skin appearance seen in the perimenopausal years. Oestrogens improve many aspects of the skin such as skin thickness, vascularization, collagen content and quality. Despite these clinical evidences, the effects of oestrogens on skin at the cellular level need further clarification.
\end{abstract}

Materials and Methods $\mathrm{HaCaT}$ and human fibroblasts were cultured under various conditions with $\mathrm{E}_{2}$ and $\mathrm{H}_{2} \mathrm{O}_{2}$; then were subjected to immunofluorescence and western blot analysis. Lipoperoxidation was investigated using BODIPY.

Results In human fibroblasts oxidative stress decreases procollagen-I synthesis, while $\mathrm{E}_{2}$ significantly increases it. Fibroblasts and $\mathrm{HaCaT}$ cells viability in the presence of $\mathrm{E}_{2}$ demonstrates a notably increased resistance to $\mathrm{H}_{2} \mathrm{O}_{2}$ effects. Furthermore $\mathrm{E}_{2}$ is able to counteract $\mathrm{H}_{2} \mathrm{O}_{2}$-mediated lipoperoxidation and DNA oxidative damage in skin cells.

Discussion In this study we highlight that the menopause-associated oestrogens decline is involved in reduced collagen production and that $E_{2}$ could counteract the detrimental effects of oxidative stress on the dermal compartment during skin aging. Furthermore, our data show that physiological concentrations of oestrogens are able to interfere with ROS-mediated cell viability reduction and to protect human skin cells against oxidative damage to cellular membranes and nucleic acids structure.

Conclusion Our experimental data show that the presence of $17 \beta$-estradiol may protect skin cells against oxidative damage and that the dramatic lowering of oestrogen levels during menopause, could render skin more susceptible to oxidative damage.

Received: 27 April 2012; Accepted: 13 August 2012

\section{Conflict of Interest}

The authors declare no conflicting or competing commercial interests.

\section{Funding source}

None.

\section{Introduction}

The ageing process involves the whole body and appears visibly in the skin. Skin ageing is influenced by several factors including genetics, environmental exposure, hormonal changes and metabolic processes. These factors together lead to cumulative alterations of skin structure, function and appearance. Clinical signs of natural ageing include fine wrinkles and skin laxity while photo- aged skin appears dry, with coarse wrinkles and uneven pigmentation. However, both processes share common features such as reduced collagen levels in the dermis resulting from decreased procollagen synthesis and increased collagen degradation. ${ }^{1}$ Collagen-I is the major structural protein of the dermis and provides strength and resiliency to the skin. Collagen-I is primarily produced by dermal fibroblasts and is regulated by a variety of mediators including 
growth factors, cytokines, hormones and mechanical tension. ${ }^{2}$ In aged skin, a dramatic decrease in procollagen synthesis by fibroblasts is evident. ${ }^{3}$ The decrease of oestrogens during menopause is associated with increased skin dryness ${ }^{4}$ and decreased skin elasticity, ${ }^{5}$ dermal thickness ${ }^{6}$ and skin collagen content. ${ }^{7}$

Various studies have shown that oestrogen therapy (ET) improve skin hydration ${ }^{8}$ and elasticity, ${ }^{9}$ higher density of collagen fibres, ${ }^{10,11}$ fewer wrinkles ${ }^{12,13}$ and thicker skin. ${ }^{14}$ Although many evidences highlighted the beneficial effects of oestrogen on skin, some studies did not show remarkable improvements with ET. ${ }^{15,16}$ Thus, the effects of oestrogens on skin are somewhat controversial and still need further evaluations. ${ }^{17}$

Oxidative stress (OS) is considered a primary feature in driving the ageing process. Ageing has been considered the consequence of free radical damage by various endogenous reactive oxygen species (ROS), according to the original free radical theory of ageing. ${ }^{18,19}$ ROS form as a natural by-product of the normal cellular metabolism and have important roles in cell signalling and homeostasis. ROS production and release can be influenced by environmental factors such as UV radiation and exogenous toxins (i.e. nitric oxide and cigarette smoke). Key ROS include superoxide $\left(\cdot \mathrm{O}_{2}{ }^{-}\right)$, hydroxyl radical $(\cdot \mathrm{OH})$ and hydrogen peroxide $\left(\mathrm{H}_{2} \mathrm{O}_{2}\right)$. Increased ROS can overwhelm antioxidant defences causing damage to DNA (mutations/breaks), proteins (nitrotyrosinylation), lipids (peroxidation) and sugars. ${ }^{20-22}$ Oxidative damage can compromise cell survival, ${ }^{23,24}$ proliferation, ${ }^{24-26}$ differentiation ${ }^{24,27,28}$ and metabolism. ${ }^{29-31}$ Long-term effects of oxidative damage are implicated in skin ageing, cancer ${ }^{32}$ and inflammation. ${ }^{33}$ In particular, in photodamaged and chronologically aged human skin, the increased OS leads to the induction of AP-1 and NF- $\kappa$ B transcription factors, ${ }^{1,34}$ which consequently induce collagen degradation by matrix metalloproteinases (MMPs) upregulation. ${ }^{1,35}$ These data have been confirmed in different experimental models. ${ }^{1,34,35}$

Many data indicate that, in nervous and cardiovascular systems, oestrogens act as antioxidant, ${ }^{36,37}$ providing a protective mechanism against ROS-induced oxidative damage. These data may be extrapolated to the hypothesis that $17 \beta$-estradiol $\left(\mathrm{E}_{2}\right)$ could exert similar beneficial effects in human skin.

\section{Materials and methods}

\section{Materials}

Phenol red-free Dulbecco's modified Eagle's medium (PRFDMEM) and phosphate buffered saline (PBS) were from Gibco (Milan, Italy). Bicinchoninic acid (BCA) protein assay was from Pierce (Rockford, IL, USA). Horseradish peroxidase (HRP)conjugated anti-mouse antibody was from Millipore (Milan, Italy). Mouse monoclonal antibody against 8-hydroxy-2'-deoxyguanosine $(8-\mathrm{OHdG})$, mouse monoclonal antibody against procollagenI $\alpha 2$ and mouse monoclonal antibody against $\beta$-actin were purchased from Santa Cruz Biotechnology (Santa Cruz, CA, USA). Alexa Fluor 488-conjugated anti-mouse was from Molecu- lar Probes (Eugene, OR, USA). BODIPY fluorescent probe was from Invitrogen (Milan, Italy). Unless otherwise specified, all other chemicals were from Sigma-Aldrich (Milan, Italy).

\section{Cell culture}

Normal human skin fibroblast cultures were established from a punch biopsy obtained from healthy female donors undergoing routine minor elective surgery. Briefly, skin specimens were cut into $1-\mathrm{mm}^{2}$ sections and incubated for $1 \mathrm{~h}$ in a $5 \% \quad \mathrm{CO}_{2}$ atmosphere at $37{ }^{\circ} \mathrm{C}$ in DMEM supplemented with dispase to facilitate separation of the epidermis from the dermis. Human dermal fibroblasts were obtained from explant cultures of the deepidermized dermis. Fibroblast cultures derived from three healthy donors were polled and maintained in PRF-DMEM supplemented with $10 \%$ fetal bovine serum (FBS), 100 units/mL penicillin and $100 \mu \mathrm{g} / \mathrm{mL}$ streptomycin (P/S). The immortalized human keratinocytes cell line HaCaT was kindly provided by Dr. V. Barygina (Department of Biochemical Sciences, University of Florence, Florence, Italy) and was cultured under the same conditions. For all experiments, cells were grown to $80 \%$ confluence and serum starved for $24 \mathrm{~h}$ before treatment.

\section{Immunofluorescence analysis}

Dermal fibroblasts and HaCaT keratinocytes $\left(1 \times 10^{6}\right)$ were seeded onto glass slides and incubated in a $5 \% \mathrm{CO}_{2}$ atmosphere at $37^{\circ} \mathrm{C}$ in PRF-DMEM supplemented with $10 \% \mathrm{FBS}$ and $1 \% \mathrm{P} / \mathrm{S}$. After $24 \mathrm{~h}$, the medium was changed to PRF-DMEM without FBS, supplemented with $1 \% \mathrm{P} / \mathrm{S}$. Cells were treated with $\mathrm{E}_{2}$ (1 nM) solubilized in absolute ethanol or with vehicle control for $48 \mathrm{~h}$, then washed twice with PBS and fixed for $10 \mathrm{~min}$ in $3.7 \%$ paraformaldehyde (PFA). After three washes with PBS, non-specific sites were blocked by incubating with $1 \%$ bovine serum albumin (BSA) at $37{ }^{\circ} \mathrm{C}$ for $15 \mathrm{~min}$. Cells were washed with PBS containing 3\% BSA for $30 \mathrm{~min}$ at room temperature (RT) and incubated with anti-procollagen-I $\alpha 2$ primary antibody diluted in PBS plus $3 \%$ BSA and $0.5 \%$ saponin, for $30 \mathrm{~min}$ at $37^{\circ} \mathrm{C}$ and then for $1 \mathrm{~h}$ at $4{ }^{\circ} \mathrm{C}$. The cells were washed three times $(15 \mathrm{~min}$ each) in PBS plus $0.5 \%$ saponin (washing buffer) and incubated with Alexa Fluor 488-conjugated anti-mouse secondary antibody in washing buffer for $30 \mathrm{~min}$ at RT. The cells were washed three times with PBS, dried, mounted with Fluoromount and examined with a Zeiss Axiolab microscope (Carl Zeiss, Milan, Italy).

\section{Western blot analysis}

Human dermal fibroblasts were treated with vehicle (48 h), $\mathrm{E}_{2}$ (1 nм; $48 \mathrm{~h}), \mathrm{H}_{2} \mathrm{O}_{2}(50 \mu \mathrm{m} ; 16 \mathrm{~h})$. The cells were also treated for $16 \mathrm{~h}$ with $\mathrm{H}_{2} \mathrm{O}_{2}(50 \mu \mathrm{M})$ after a 48 -h pretreatment with $\mathrm{E}_{2}$ (1 nM). The cells were washed three times with ice-cold PBS, scraped off the plates and lysed in $1 \mathrm{~mL}$ RIPA lysis buffer $(50 \mathrm{~mm}$ Tris- $\mathrm{HCl}$, pH 7.5, $150 \mathrm{~mm} \mathrm{NaCl}, 1 \mathrm{~mm} \mathrm{Na} \mathrm{VO}_{3}, 1 \mathrm{~mm} \mathrm{NaF}, 1$ mM EGTA, $1 \mathrm{~mm}$ EDTA, 1\% Nonidet P-40, 0.25\% sodium deoxycholatey) containing a protease inhibitor cocktail. The protein concentration 
was estimated by BCA assay, and equal amounts of total protein $(15 \mu \mathrm{g})$ from each sample were separated by SDS-PAGE and transferred to nitrocellulose membranes. Non-specific sites were blocked for 1 hat RT with milk powder. The membranes were incubated overnight at $4{ }^{\circ} \mathrm{C}$ with anti-procollagen-I $\alpha 2$ antibody. After washing, blots were incubated with HRP-conjugated antimouse antibody for $1 \mathrm{~h}$ at RT. After washing, blots were incubated with peroxidase chemiluminescence substrate and signals were detected using ChemiDoc XRS system (Bio-Rad, Milan, Italy). Band intensities were determined by densitometric analysis (ImageJ). Reprobing of the membrane with a $\beta$-actin antibody was used to verify equal protein loading.

\section{Mitochondrial activity assay}

Mitochondrial activity was assessed by the 3-(4,5-dimethylthiazol2-yl)-2,5-diphenyltetrazoliumbromide (MTT) assay in 96-well plates. The cells were treated with increasing concentration of $\mathrm{H}_{2} \mathrm{O}_{2}(50-250 \mu \mathrm{M})$, alone or in the presence of $\mathrm{E}_{2}$ (1 nM) for $24 \mathrm{~h}$. After washing with PBS, $0.5 \mathrm{mg} / \mathrm{mL}$ MTT solution in PRF-DMEM was added to the cell cultures and the samples were incubated for $4 \mathrm{~h}$ at $37^{\circ} \mathrm{C}$. Finally, MTT formazan crystals were resolubilized by adding dimethylsulfoxide (DMSO) to each well. Plates were agitated on a plate shaker for $5 \mathrm{~min}$ and spectrophotometric absorbance at $590 \mathrm{~nm}$ was then determined using an ELISA plate reader. Cell viability was expressed as a percentage of MTT reduction.

\section{Evaluation of lipid peroxidation}

Lipid peroxidation was investigated in fibroblasts and $\mathrm{HaCaT}$ using BODIPY 581/591, a fluorescent probe that is intrinsically lipophilic and thus mimics the properties of natural lipids. BODIPY acts as a fluorescent lipid peroxidation reporter that shifts its fluorescence from red to green in the presence of oxidizing agents. Briefly, cells were cultured on glass slides and treated with vehicle (24 h), $\mathrm{E}_{2}(1 \mathrm{~nm} ; 24 \mathrm{~h})$ and $\mathrm{H}_{2} \mathrm{O}_{2}(70 \mu \mathrm{M} ; 16 \mathrm{~h})$. The cells were also treated with $\mathrm{H}_{2} \mathrm{O}_{2}(70 \mu \mathrm{M})$ for $16 \mathrm{~h}$ after a 24 -h pretreatment with $\mathrm{E}_{2}(1 \mathrm{nM})$. The cells were then loaded with dye by adding BODIPY, dissolved in 0.1\% DMSO (2.5 $\mu \mathrm{m}$ final concentration), to the cell culture media for $30 \mathrm{~min}$ at $37^{\circ} \mathrm{C}$. The cells were fixed in $3.7 \%$ PFA for $10 \mathrm{~min}$ at RT and the BODIPY fluorescence was analysed (at an excitation wavelength of $581 \mathrm{~nm}$ ) using a Zeiss Axiolab microscope. Moreover, lipid peroxidation was quantified by flow cytometry. Cell suspensions were washed twice with PBS and incubated in the dark for $30 \mathrm{~min}$ at $37^{\circ} \mathrm{C}$ with BODIPY. Cells were washed and resuspended in PBS. Green fluorescence and red fluorescence were revealed, respectively, by the FL-1 (515-555 nm wavelength band) and the FL-2 (563-607 nm wavelength band) detectors of a FACScan flow
Figure 1 Effects of $17 \beta$-estradiol and oxidative stress on procollagen-I synthesis. $(a-c)$ Immunofluorescence microscopy of human dermal fibroblasts and $\mathrm{HaCaT}$ keratinocytes immunolabeled using anti-procollagen-I $\alpha 2$ antibody. (a, a') control fibroblasts; (b, b') fibroblasts treated with $\mathrm{E}_{2}$ (1 nм; 48 h); (c, c') HaCaT. (a-c magnification 40x; a', b', c' magnification 100x). Scale bar: $10 \mu$ m. (d) Western blot analysis. The samples were normalized for protein loading $(15 \mu \mathrm{g})$ by reblotting the membrane with a $\beta$-actin antibody. Relative band intensities are depicted in histograms. Data from three independent experiments were combined and analysed by ANOVA. ${ }^{*} P<0.001$ vs. control, ${ }^{\circ} P<0.05$ vs. control, $\S P<0.001$ vs. $\mathrm{H}_{2} \mathrm{O}_{2}$.
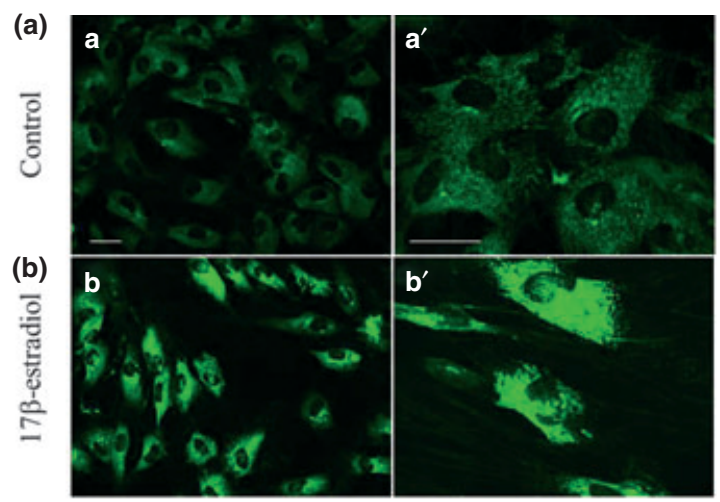

(c)

(d)
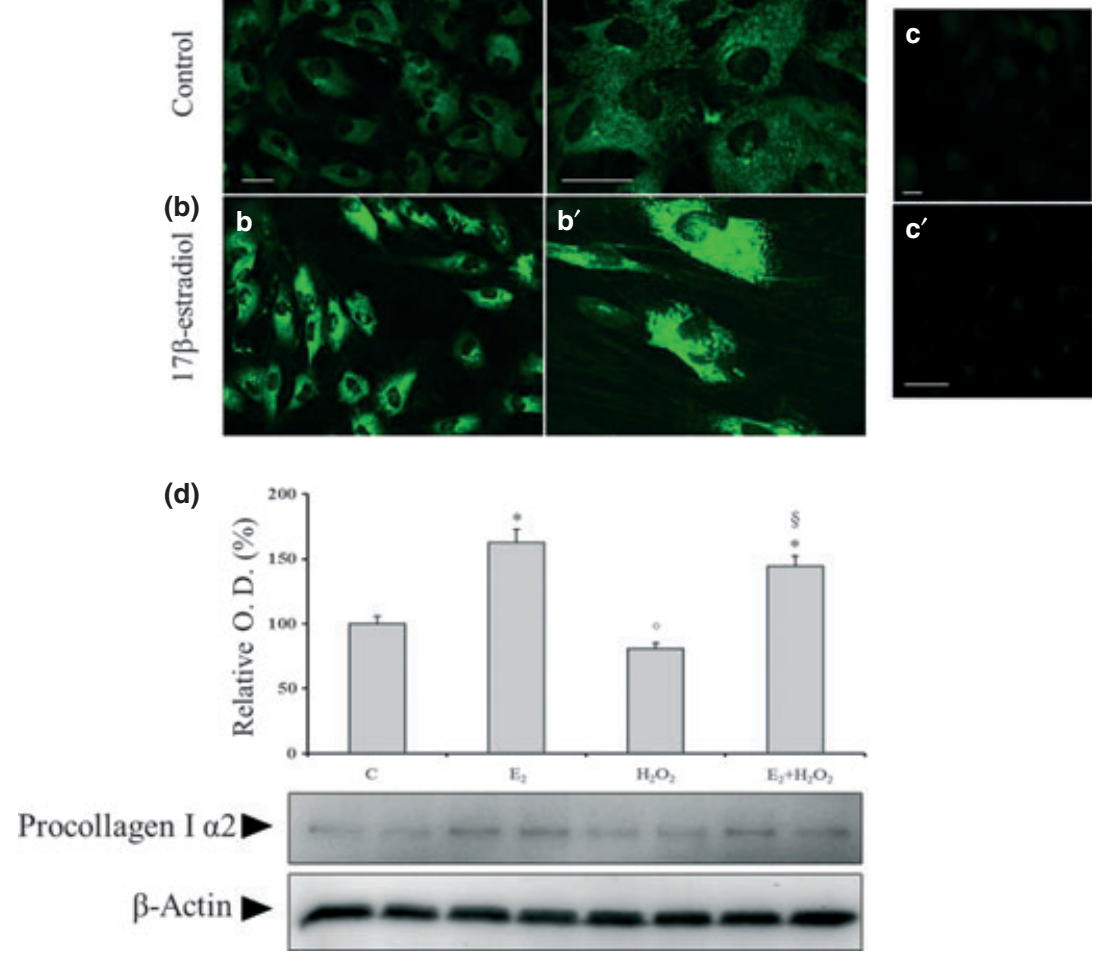
cytometer (Becton Dickinson, San Jose, CA, USA) equipped with a 15-mW argon-ion laser for excitation.

\section{Evaluation of nucleic acids oxidation}

Nucleic acid oxidation was investigated using an antibody against 8-OHdG, the most distinctive oxidative biomarker of DNA damage. Human fibroblasts and $\mathrm{HaCaT}$ were cultured on glass slides and treated under the same conditions described for lipid peroxidation analysis. Cells were fixed for $10 \mathrm{~min}$ in 3.7\% PFA and subjected to the immunofluorescence protocol previously described. Hoechst 33342 was used for the nuclear staining. Moreover, nucleic acids oxidation was quantified by flow cytometry. Briefly, the cell suspensions were washed twice with PBS and fixed in $3.7 \%$ PFA for $10 \mathrm{~min}$ at RT. After three washes with PBS, the samples were incubated with the 8 -OHdG antibody diluted in $0.1 \% \mathrm{Na}$ citrate and $0.1 \%$ Triton-X100 for $1 \mathrm{~h}$ at $37{ }^{\circ} \mathrm{C}$. The suspensions were washed twice with $\mathrm{PBS}$ plus $1 \%$ normal goat serum (washing buffer), and then incubated with a FITC-conjugated anti-mouse secondary antibody. After two washes in the washing buffer, the cells were resuspended in PBS. Green fluorescence was revealed by the FL-1 (515-555 nm wavelength band) detectors of a FACScan flow cytometer equipped with a 15-mW argon-ion laser for excitation.

\section{Statistical analysis}

All data are reported as mean \pm SD of three independent experiments. Statistical analysis was performed using one-way ANOVA. A $P$ value $<0.05$ was considered significant. The $\mathrm{IC}_{50}$ values were calculated using the ALLFIT program. ${ }^{19}$

\section{Results}

Human primary dermal fibroblasts were subjected to immunofluorescence and western blot analysis to investigate the role of $\mathrm{E}_{2}$ and $\mathrm{H}_{2} \mathrm{O}_{2}$ on procollagen-I synthesis. Figure $1 \mathrm{a}, \mathrm{b}$ shows the
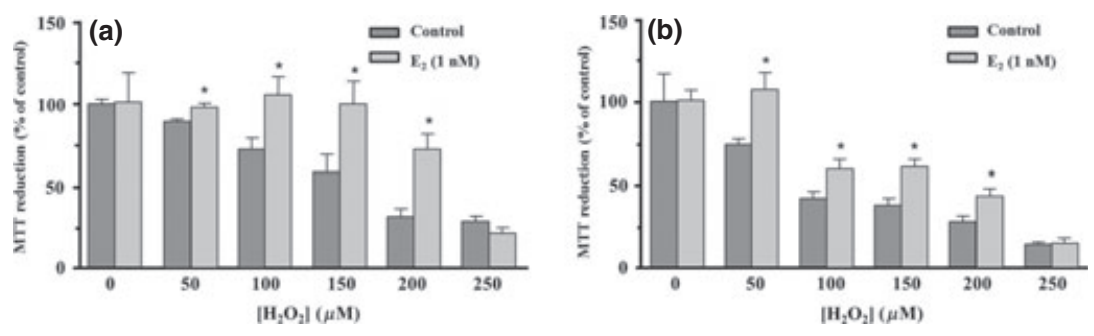

Figure 2 Mitochondrial activity assay performed on human dermal fibroblasts (a) and $\mathrm{HaCaT}$ keratinocytes (b) treated with increasing concentrations of $\mathrm{H}_{2} \mathrm{O}_{2}$ (50-250 $\mu \mathrm{M})$ in absence or in presence of $\mathrm{E}_{2}(1 \mathrm{~nm})$ for 24 h. ${ }^{*} P<0.001$ vs. $\mathrm{H}_{2} \mathrm{O}_{2}$.
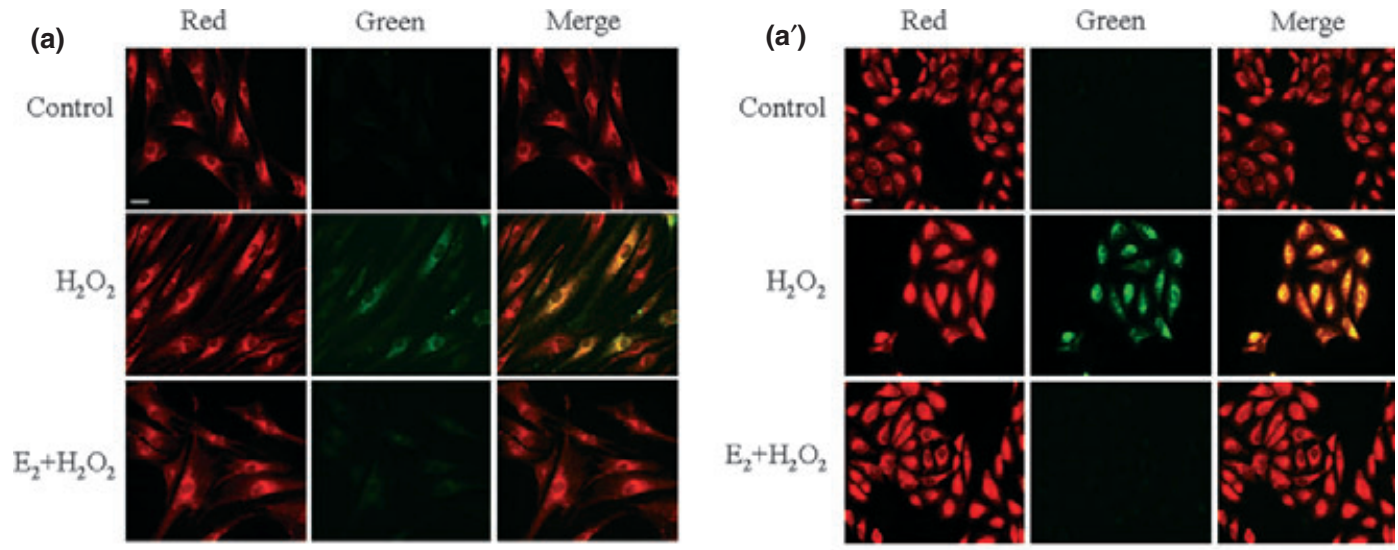

(b)
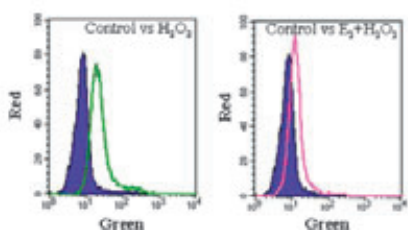

(b')

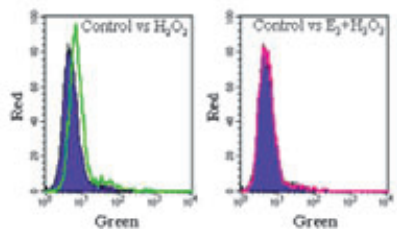

Figure 3 Fluorescence microscopy and flow cytometry analysis of lipid peroxidation. (a, a') Fluorescence microscopy analysis of lipoperoxidation in dermal fibroblasts (a) and HaCaT (a'). BODIPY shifts its fluorescence from red to green in the presence of oxidizing agents. Merged images show an overlap of the red and green fluorescence of BODIPY. Scale bar: $20 \mu \mathrm{M}$. (b, b') Quantitative analysis of lipoperoxidation by flow cytometry in dermal fibroblasts (b) and $\mathrm{HaCaT}$ (b'). 
specific immunoreactivity for procollagen-I $\alpha 2$ observed in the pooled cells obtained by skin dermal biopsies of three different patients. A stronger positivity was observed in $\mathrm{E}_{2}(1 \mathrm{nM})$ treated cells (Fig. 1a; panels b, b') with respect to control cells (Fig. 1a; panels $a, a$ '). The specificity of staining was demonstrated through the complete absence of labelling obtained using an isotype control in the control samples (data not shown) and HaCaT keratinocytes as negative control (Fig. 1c). These results, according to previous data, ${ }^{7,38,39}$ highlight that the menopause-associated oestrogens decline could account for the reduced collagen production. To test the hypothesis that $\mathrm{E}_{2}$ could interfere with OS-mediated collagen decrease, we analysed the procollagen-I expression in control and $\mathrm{E}_{2}$ (1 nM) 48-h pretreated cells by inducing OS with $\mathrm{H}_{2} \mathrm{O}_{2}(50 \mu \mathrm{M}$; $12 \mathrm{~h}$ ). Western blot analysis shown in Fig. 1d confirmed that $\mathrm{E}_{2}$ increases procollagen-I $\alpha 2$ expression $(P<0.001)$, while $\mathrm{H}_{2} \mathrm{O}_{2}$ decreased it $(P<0.05)$. Furthermore, $\mathrm{E}_{2}$ pretreatment prevented OS-induced collagen decrease $(P<0.001)$ and increased collagen content with respect to control $(P<0.001)$. These results support the previous findings that ROS mediate alterations of skin connective tissue $^{40}$ and demonstrate that $\mathrm{E}_{2}$ could prevent the ROS-induced procollagen-I synthesis decrease in human dermal fibroblasts, suggesting a plausible protective role of $\mathrm{E}_{2}$ against OS-mediated skin damage during ageing.

To better assess the potential protective effects of $E_{2}$ against $O S$ in skin, we performed MTT assay on human dermal fibroblasts and $\mathrm{HaCaT}$ keratinocytes (Fig. 2a,b). Fibroblasts and $\mathrm{HaCaT}$ were incubated for $24 \mathrm{~h}$ with increasing concentrations of $\mathrm{H}_{2} \mathrm{O}_{2}$ $(50-250 \mu \mathrm{M})$ in absence or in presence of $\mathrm{E}_{2}(1 \mathrm{nM})$. The mitochondrial activity measured using MTT test demonstrated a sigmoidal relationship between cell viability and $\mathrm{H}_{2} \mathrm{O}_{2}$ concentration with an $\mathrm{IC}_{50}$ of $158.9 \pm 9.3 \mu \mathrm{M}$ for fibroblasts (Fig. 2a) and of $91 \pm 16 \mu \mathrm{m}$ for $\mathrm{HaCaT}$ (Fig. 2b). Fibroblasts and $\mathrm{HaCaT}$ viability measured in the presence of $\mathrm{E}_{2} 1 \mathrm{nM}$ demonstrated a significantly increased resistance to $\mathrm{H}_{2} \mathrm{O}_{2}$ treatment, with an $\mathrm{IC}_{50}$ of $219.9 \pm 3.55 \mu \mathrm{M}$ for fibroblasts (Fig. 2a) and of $151 \pm 18 \mu \mathrm{M}$ for $\mathrm{HaCaT}$ (Fig. 2b). The cells treated with $\mathrm{E}_{2}$ showed an increased tendency to resist against $\mathrm{H}_{2} \mathrm{O}_{2}$ adverse effects, giving a further demonstration of the $\mathrm{E}_{2}$ protective role against $\mathrm{OS}$.

To evaluate a possible interference mechanism of oestrogen with ROS-induced oxidative damage, we analysed the effects of $\mathrm{E}_{2}$ on $\mathrm{H}_{2} \mathrm{O}_{2}$-induced lipoperoxidation. Lipid peroxidation was investigated on dermal fibroblasts and $\mathrm{HaCaT}$ by fluorescence microscopy analysis using the lipophilic fluorescent probe BODIPY (Fig. 3a,a'). The probe was not oxidized in control cells, whereas the treatment with $\mathrm{H}_{2} \mathrm{O}_{2}(70 \mu \mathrm{M})$ for $16 \mathrm{~h}$ is capable of considerably increasing the lipid peroxidation (Fig. 3a,a'). Both cellular types were protected against $\mathrm{H}_{2} \mathrm{O}_{2}$-induced lipoperoxidation by a 24-h pretreatment with $\mathrm{E}_{2}$ (1 nM), which can bring the lipoperoxidation rate back to comparable levels to control cells (Fig. 3a,a'). These results were confirmed by flow cytometry analysis, as shown

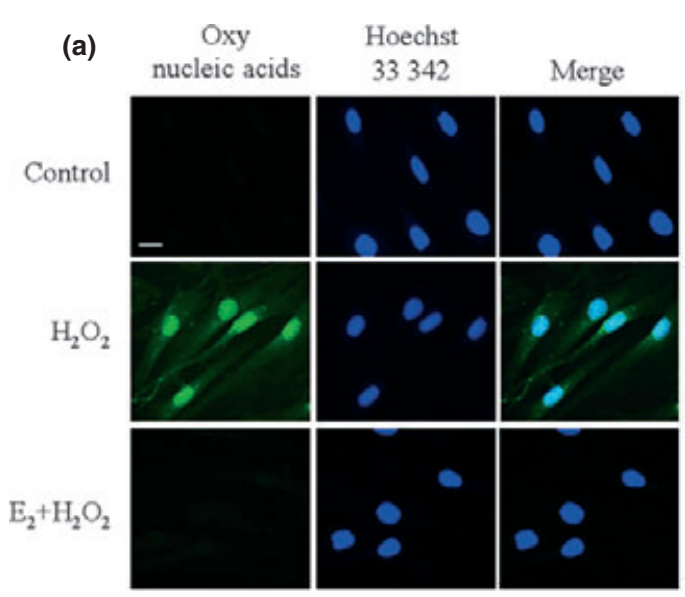

(b)

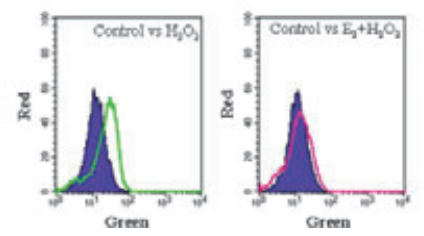

(a')

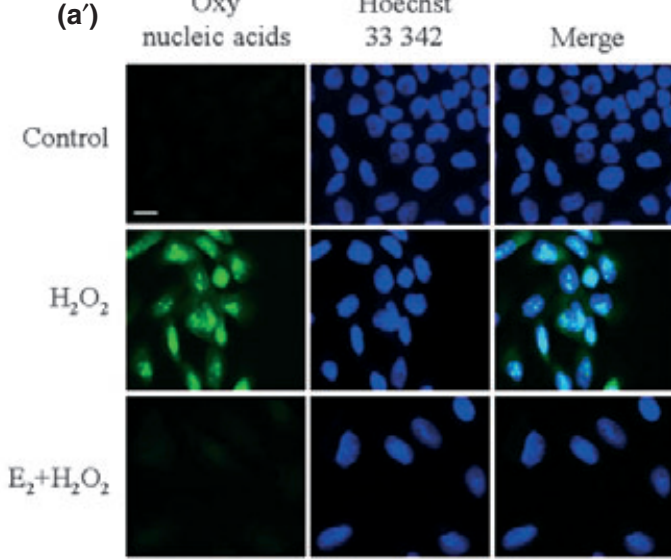

(b')

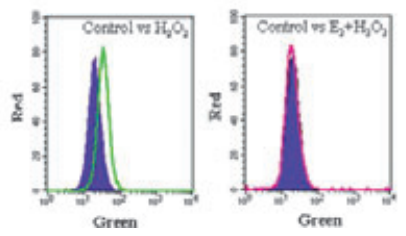

Figure 4 Fluorescence microscopy and flow cytometry analysis of nucleic acids oxidation. (a, a') Fluorescence microscopy analysis of nucleic acids oxidation in human dermal fibroblasts (a) and HaCaT (a'). Oxy nucleic acids staining shows nucleic acids damage (green). Nuclei were stained (Hoechst 33342, blue). Merged images show an overlap of 8-OHdG with Hoechst 33342. Scale bar; $10 \mu \mathrm{m}$. (b, b') Quantitative analysis of nucleic acids oxidation by flow cytometry in human dermal fibroblasts (b) and HaCaT (b'). 
in Fig. 3b,b'. In both cellular types, a significant shift of $\mathrm{H}_{2} \mathrm{O}_{2}$ treated cells ( $P<0.001$, green curves) with respect to control (purple curves) was observed. This shift is significantly reverted $\left(P<0.001\right.$, vs. $\mathrm{H}_{2} \mathrm{O}_{2}$ treated cells) by the $\mathrm{E}_{2}$ pretreatment (pink curves).

Nucleic acids oxidation was evaluated by immunofluorescence microscopy analysis on dermal fibroblasts and HaCaT co-stained with a specific anti-8OHdG antibody and Hoechst 33342 (Fig. 4a,a'). The cells treated with $\mathrm{H}_{2} \mathrm{O}_{2}(70 \mu \mathrm{M})$ for $16 \mathrm{~h}$ showed an increased green fluorescence intensity caused by the rise of nuclear 8-OHdG level, whereas in control cells, no significant fluorescent signal was detected (Fig. 4a,a'). Once more the 24-h pretreatment with $\mathrm{E}_{2}(1 \mathrm{nM})$ was capable of protecting both cell types against $\mathrm{H}_{2} \mathrm{O}_{2}$ oxidative effects (Fig. $4 \mathrm{a}$,a'). The quantitative flow cytometry analysis confirms these results (Fig. 4b,b'). The treatment with $\mathrm{H}_{2} \mathrm{O}_{2}$ induced a considerable shift of oxidized cells ( $P<0.001$, green curves) with respect to control (purple curves), whereas the $\mathrm{E}_{2}$ pretreatment (pink curves) reverted completely this effect $\left(P<0.001\right.$, vs. $\mathrm{H}_{2} \mathrm{O}_{2}$ treated cells).

\section{Discussion}

Human skin is subject to an unavoidable intrinsic ageing process. In addition, skin ageing is strongly influenced by exogenous factors such as UV radiation, which may cause premature skin ageing, also referred to as photoageing or extrinsic skin ageing. However, both intrinsic and extrinsic processes share major biochemical features such as reduced collagen content in the dermis, resulting from increased collagen degradation and decreased procollagen synthesis. ${ }^{1}$ Oestrogens exert a profound influence on skin, as highlighted by regressive cutaneous changes that occur after menopause in women. ${ }^{7,38,41}$ They not only increase skin thickness and enhance vascularization but also improve collagen content and quality. ${ }^{39}$ Our results confirm that $\mathrm{E}_{2}$ stimulates procollagen-I synthesis in human cultured skin fibroblasts and highlight that the menopause-associated oestrogen decline is involved in reduced collagen production.

OS is considered a primary driving force of the ageing process. The free radical theory of ageing ${ }^{18,19}$ describes the progressive accumulation of damage by ROS over a lifetime as a result of aerobic metabolism, combined with a decline in antioxidant defences. ROS such as $\mathrm{H}_{2} \mathrm{O}_{2}$ were suggested to increase the induction of MMPs in keratinocytes and fibroblasts, ${ }^{42}$ resulting in sustained collagen degradation and reduced mechanical tension. Partially degraded collagen and reduced mechanical tension of fibroblasts inhibit new procollagen synthesis and lead to further production of ROS, generating a selfperpetuating cycle, which is a critical mechanism of human skin ageing. ${ }^{40,43}$

We tested the hypothesis that $\mathrm{E}_{2}$ could exert beneficial effects on OS-mediated collagen decrease by western blot analysis. Our results demonstrate that $\mathrm{E}_{2}$ could interfere with ROS-induced procollagen-I synthesis decrease in human dermal fibroblasts, counteracting the detrimental effects of OS on the dermal compartment during skin ageing. Furthermore, our results obtained by MTT assay clearly demonstrate that oestrogens are not only involved in the collagen synthesis pathway, but could also interfere with ROS-mediated viability reduction in human dermal fibroblasts and $\mathrm{HaCaT}$ keratinocytes, giving a further demonstration of the $\mathrm{E}_{2}$ protective role against $\mathrm{OS}$ in human skin.

Ageing is associated with changes in the molecular structure of DNA, proteins and lipids - all markers of OS. Although transient fluctuations in ROS serve important regulatory functions, when present at high and/or sustained levels, ROS can cause severe damage to these molecules. Considering that an increase in ROS levels has been observed during ageing, ${ }^{44}$ the importance of oestrogen-related protective effects need to be considered.

To explore the plausible protective action of $\mathrm{E}_{2}$ against OS-induced cellular damage, we evaluated two of the major oxidative stress markers within cells, lipoperoxidation and DNA oxidative damage. Lipoperoxidation process proceeds by a free radical chain reaction mechanism when the cellular peroxidized membranes lose their permeability and integrity. DNA oxidative damage can compromise the cellular function, and it is probably the major factor involved in mutagenesis, carcinogenesis and ageing. ${ }^{45}$ 8-OHdG induces a guanine to thymine base transversion in DNA structure and thus is considered one of the main biomarkers of oxidative damage. Our data show that physiological concentrations of oestrogens are able to protect human skin cells against oxidative damage to cellular membranes and nucleic acids structure. Considering the high levels of cutaneous ROS generated during UV exposition and also during intrinsic ageing, our data suggested that the dramatic lowering of oestrogen levels during menopause could make skin more sensitive to oxidative damage caused by ROS and that oestrogens could offer a global protection against OS by improving cellular ability to resist against ROS damaging effects.

Although ET has been used for many years to treat the symptoms of menopause and to prevent postmenopausal osteoporosis, recent trials have reported a significant increased risk of breast cancer and other pathologies with this treatment. ${ }^{46-48}$ For these reasons, systemic ET cannot be recommended to treat skin ageing. Phytoestrogens, non-steroidal plant compounds with oestrogenlike biological activity, such as Diadzen, Genistein and Resveratrol seem promising alternatives for skin ageing treatment. However, the precise mechanism of action of phytoestrogens in skin is still unknown, and their possible side-effects have not been well investigated.

\section{Acknowledgement}

We are grateful to the family of Dr Luna Trollini for honouring our work with the Luna Trollini memory Award. 


\section{References}

1 Rittiè L, Fisher GJ. UV-light-induced signal cascades and skin aging. Ageing Res Rev 2002; 1: 705-720.

2 Eckes B, Zweers MC, Zhang ZG et al. Mechanical tension and integrin alpha 2 beta 1 regulate fibroblast functions. J Investig Dermatol Symp Proc 2006; 11: 66-72.

3 Varani J, Dame MK, Rittiè L et al. Decreased collagen production in chronologically aged skin: roles of age-dependent alteration in fibroblast function and defective mechanical stimulation. Am J Pathol 2006; 168: 1861-1868.

4 Bolognia JL, Braverman IM, Rousseau ME et al. Skin changes in menopause. Maturitas 1989; 11: 295-304.

5 Sumino H, Ichikawa S, Abe $\mathrm{M}$ et al. Effects of aging and postmenopausal hypoestrogenism on skin elasticity and bone mineral density in Japanese women. Endocr J 2004; 51: 159-164.

6 Chotnopparatpattara P, Panyakhamlerd K, Taechakraichana N et al. An effect of hormone replacement therapy on skin thickness in early postmenopausal women. J Med Assoc Thai 2001; 84: 1275-1280.

7 Affinito P, Palomba S, Sorrentino C et al. Effects of postmenopausal hypoestrogenism on skin collagen. Maturitas 1999; 33: 239-247.

8 Sator PG, Schmidt JB, Sator MO et al. The influence of hormone replacement therapy on skin ageing: a pilot study. Maturitas 2001; 39: 43-55.

9 Sumino H, Ichikawa S, Abe $\mathrm{M}$ et al. Effects of aging, menopause, and hormone replacement therapy on forearm skin elasticity in women. J Am Geriatr Soc 2004; 52: 945-949.

10 Rittié L, Kang S, Voorhees JJ, Fisher GJ. Induction of collagen by estradiol: difference between sun-protected and photodamaged human skin in vivo. Arch Dermatol 2008; 144: 1129-1140.

11 Son ED, Lee JY, Lee S et al. Topical application of 17beta-estradiol increases extracellular matrix protein synthesis by stimulating TGF-Beta signaling in aged human skin in vivo. J Invest Dermatol 2005; 124: 1149-1161.

12 Wolff EF, Narayan D, Taylor HS. Long-term effects of hormone therapy on skin rigidity and wrinkles. Fertil Steril 2005; 84: 285-288.

13 Sator PG, Sator MO, Schmidt JB et al. A prospective, randomised, double-blind, placebo-controlled study on the influence of a hormone replacement therapy on skin aging in postmenopausal women. Climacteric 2007; 10: 320-334.

14 Patriarca MT, Goldman KZ, Dos Santos JM et al. Effects of topical estradiol on the facial skin collagen of postmenopausal women under oral hormone therapy: a pilot study. Eur J Obstet Gynecol Reprod Biol 2007; 130: 202-205.

15 Sauerbronn AV, Fonseca AM, Bagnoli VR et al. The effects of systemic hormonal replacement therapy on the skin of postmenopausal women. Int J Gynaecol Obstet 2000; 68: 35-41.

16 Haapasaari KM, Raudaskoski T, Kallioinen M et al. Systemic therapy with estrogen or estrogen with progestin has no effect on skin collagen in postmenopausal women. Maturitas 1997; 27: 153-162.

17 Hall G, Phillips TJ. Estrogen and skin: the effects of estrogen, menopause, and hormone replacement therapy on the skin. J Am Acad Dermatol 2005; 53: 555-568.

18 Harman D. The free radical theory of aging. Antioxid Redox Signal 2003; 5: 557-561.

19 Harman D. Free radical theory of aging: an update: increasing the functional life span. Ann N Y Acad Sci 2006; 1067: 10-21.

20 Okayama Y. Oxidative stress in allergic and inflammatory skin diseases. Curr Drug Targets Inflamm Allergy 2005; 4: 517-519.

21 Vayalil PK, Mittal A, Hara Y et al. Green tea polyphenols prevent ultraviolet light-induced oxidative damage and matrix metalloproteinases expression in mouse skin. J Invest Dermatol 2004; 122: 14801487.

22 Ismail NS, Pravda EA, Li D et al. Angiopoietin-1 reduces $\mathrm{H}_{2} \mathrm{O}_{2}$-induced increases in reactive oxygen species and oxidative damage to skin cells. J Invest Dermatol 2010; 130: 1307-1317.
23 Guyton KZ, Gorospe M, Wang X et al. Age-related changes in activation of mitogen-activated protein kinase cascades by oxidative stress. J Investig Dermatol Symp Proc 1998; 3: 23-27.

24 Bickers DR, Athar M. Oxidative stress in the pathogenesis of skin disease. J Invest Dermatol 2006; 126: 2565-2575.

25 Kawanishi S, Hiraku Y, Oikawa S. Mechanism of guanine specific DNA damage by oxidative stress and its role in carcinogenesis and aging. Mutat Res 2001; 488: 65-76.

26 Shilov VN, Sergienko VI. Oxidative stress in keratinocytes as an etiopathogenetic factor of psoriasis. Bull Exp Biol Med 2000; 129: 364-369.

27 Jiménez-Cervantes C, Martínez-Esparza M, Pérez C et al. Inhibition of melanogenesis in response to oxidative stress: transient downregulation of melanocyte differentiation markers and possible involvement of microphthalmia transcription factor. J Cell Sci 2001; 114: 23352344.

28 Muramatsu S, Suga Y, Mizuno Y et al. Differentiation-specific localization of catalase and hydrogen peroxide, and their alterations in rat skin exposed to ultraviolet B rays. J Dermatol Sci 2005; 37: 151-158.

29 Halliwell B, Chirico S. Lipid peroxidation: its mechanism, measurement, and significance. Am J Clin Nutr 1993; 57(5 Suppl): 715S724 S.

30 Ma YS, Wu SB, Lee WY, Cheng JS, Wei YH. Response to the increase of oxidative stress and mutation of mitochondrial DNA in aging. Biochim Biophys Acta 2009; 1790: 1021-1029.

31 Cecarini V, Gee J, Fioretti E et al. Protein oxidation and cellular homeostasis: Emphasis on metabolism. Biochim Biophys Acta 2007; 1773: 93-104.

32 Black HS. Potential involvement of free radical reactions in ultraviolet lightmediated cutaneous damage. Photochem Photobiol 1987; 46: 213-221.

33 Cerutti PA. Prooxidant states and tumor promotion. Science 1985; 227: 375-381.

34 Vile GF, Tanew-Ilitschew A, Tyrrell RM. Activation of NF-kappa B in human skin fibroblasts by the oxidative stress generated by UVA radiation. Photochem Photobiol 1995; 62: 463-468.

35 Tanaka K, Hasegawa J, Asamitsu K, Okamoto T. Prevention of the ultraviolet B-mediated skin photoaging by a nuclear factor kappaB inhibitor, parthenolide. J Pharmacol Exp Ther 2005; 315: 624-630.

36 Rao AK, Dietrich AK, Ziegler YS et al. 17 $\beta$-Estradiol-mediated increase in $\mathrm{Cu} / \mathrm{Zn}$ superoxide dismutase expression in the brain: a mechanism to protect neurons from ischemia. J Steroid Biochem Mol Biol 2011; 127: 382-389.

37 Strehlow K, Rotter S, Wassmann S et al. Modulation of antioxidant enzyme expression and function by estrogen. Circ Res 2003; 93: 170-177.

38 Brincat M, Moniz CF, Studd JW et al. Sex hormones and skin collagen content in postmenopausal women. Br Med J (Clin Res Ed) 1983; 287: 1337-1338.

39 Brincat MP. Hormone replacement therapy and the skin. Maturitas 2000; 29: 107-117.

40 Kohl E, Steinbauer J, Landthaler M, Szeimies RM. Skin ageing. J Eur Acad Dermatol Venereol 2011; 25: 873-884.

41 Castelo-Branco C, Duran M, Gonzalez-Merlo J. Skin collagen changes related to age and hormone replacement therapy. Maturitas 1992; 15: 113-119.

42 Brenneisen P, Briviba K, Wlaschek M, Wenk J, Scharffetter-Kochanek $\mathrm{K}$. Hydrogen peroxide $\left(\mathrm{H}_{2} \mathrm{O}_{2}\right)$ increases the steady-state mRNA levels of collagenase/MMP-1 in human dermal fibroblasts. Free Radic Biol Med 1997; 22: 515-524.

43 Fisher GJ, Quan T, Purohit T et al. Collagen fragmentation promotes oxidative stress and elevates matrix metalloproteinase-1 in fibroblasts in aged human skin. Am J Pathol 2009; 174: 101-114.

$44 \mathrm{Hu} \mathrm{HL}$, Forsey RJ, Blades TJ et al. Antioxidants may contribute in the fight against ageing: an in vitro model. Mech Ageing Dev 2000; 121: 217-230. 
45 Lindahl T. Instability and decay of the primary structure of the DNA. Nature 1993; 362: 709-715.

46 Rossouw JE, Anderson GL, Prentice RL et al. Risk and benefits of estrogen plus progestin in healthy postmenopausal women: principal results from the Women's Health Initiative randomized controlled trial. JAMA 2002; 288: 321-333.
47 Soloman CG, Dluhy RG. Rethinking post-menopausal hormone therapy. N Engl J Med 2003; 348: 579-580.

48 Hulley S, Grady D, Bush T et al. Randomized trial of estrogen plus progestin for secondary prevention of coronary heart disease in postmenopausal women. JAMA 1998; 280: 605-613. 